\title{
MRI-guided laser interstitial thermal therapy in an infant with tuberous sclerosis: technical case report
}

\author{
Kristopher G. Hooten, MD,, ${ }^{1,2,4}$ Klaus Werner, MD, PhD,,4 Mohamad A. Mikati, MD,,,4 and \\ Carrie R. Muh, MD ${ }^{1,4}$
}

${ }^{1}$ Department of Neurosurgery, ${ }^{3}$ Division of Pediatric Neurology, ${ }^{4}$ Tuberous Sclerosis Complex Clinic, Duke University, Durham, North Carolina; and ${ }^{2}$ Department of Neurosurgery, University of Florida, Gainesville, Florida

\begin{abstract}
Cortical tubers associated with tuberous sclerosis complex (TSC) are potential epileptic foci that are often amenable to resective or ablative surgeries, and controlling seizures at a younger age may lead to improved functional outcomes. MRI-guided laser interstitial thermal therapy (MRgLITT) has become a popular minimally invasive alternative to traditional craniotomy. Benefits of MRgLITT include the ability to monitor the ablation in real time, a smaller incision, shorter hospital stay, reduced blood loss, and reduced postoperative pain. To place the laser probe for LITT, however, stereotaxy is required-which classically involves head fixation with cranial pins. This creates a relative minimum age limit of 2 years old because it demands a mature skull and fused cranial sutures. A novel technique is presented for the application of MRgLITT in a 6-month-old infant for the treatment of epilepsy associated with TSC. To the authors' knowledge this is the youngest patient treated with laser ablation. The authors used a frameless navigation technique with a miniframe tripod system and intraoperative reference points. This technique expands the application of MRgLITT to younger patients, which may lead to safer surgical interventions and improved outcomes for these children.
\end{abstract}

https://thejns.org/doi/abs/10.3171/2018.6.PEDS1828

KEYWORDS MRI-guided laser ablation; tuberous sclerosis; infant; cortical tuber; epilepsy; surgical technique

$\mathrm{T}$ UBEROUS sclerosis complex (TSC) is a multisystem genetic disorder that causes benign masses to develop. Cortical and subcortical lesions form, including glioneuronal tubers, subependymal glial nodules, and subependymal giant cell astrocytomas. ${ }^{7}$ Epilepsy is reported in up to $90 \%$ of patients, and seizures are typically associated with the tubers. ${ }^{8}$ These tubers present a surgical target for seizure focus resection or ablation in drug-resistant cases. Many patients with TSC undergo multiple craniotomies or multistage surgeries for cortical mapping followed by resection of one or more cortical lesions. ${ }^{38,39,45}$

With advancement in technology, stereotactic procedures for minimally invasive treatment of epilepsy have increased in popularity. Laser interstitial thermal therapy (LITT) destroys tissue by using heat generation through light energy, resulting in DNA damage, protein denaturation, and cell death. ${ }^{20}$ MR thermal imaging uses proton resonance frequency shifts and allows precise real-time monitoring of thermal ablation zones, which can protect critical and eloquent structures. ${ }^{36,40}$ Combining these technologies in MRI-guided LITT (MRgLITT) allows for real-time monitoring and the ability to control the energy delivered to the tissue.

MRgLITT ablation for epilepsy has been shown to be as effective as resection for many patients. ${ }^{13,18,37,47} \mathrm{Ad}-$ ditional advantages include lower surgical morbidity, a smaller incision, shorter hospital stay, reduced blood loss, and reduced postoperative pain. Prior studies have reported the need for stereotactic navigation with the use of a cranial frame or fixation in cranial pins. ${ }^{11,26,34,43,44}$ As a

ABBREVIATIONS AEDs = antiepileptic drugs; DRE = drug-resistant epilepsy; EEG = electroencephalography; MRgLITT = MRI-guided laser interstitial thermal therapy; TSC = tuberous sclerosis complex. 
result, a minimum patient age of approximately 2 years is used by most epilepsy centers. Here, we report a technique in which we used frameless stereotaxy and MRgLITT for the ablation of a cortical tuber in a 6-month-old infant with medically refractory epilepsy and TSC. In previously reported pediatric series, the youngest patient was 19 months old. $4,11,14,17,24,28,43,44,47$ To the best of our knowledge, this is the first reported application of this technology in an infant.

\section{Clinical Presentation}

A prenatal ultrasound of our patient at 36 weeks' gestation demonstrated echogenic intracardiac rhabdomyomas. An MRI sequence after birth demonstrated a large right frontal cortical lesion, and the patient was diagnosed with TSC. At 7 weeks of age, her parents noted "zoning out" episodes throughout the day. An electroencephalography (EEG) study was performed, which demonstrated right frontocentral interictal discharges and multiple subclinical seizures occurring every 15 minutes, each lasting 2030 seconds. The patient underwent 3 hospitalizations to improve seizure control with multiple antiepileptic drugs (AEDs) and to better characterize epileptic events with video EEG monitoring. Figure 1 demonstrates the right frontal cortical tuber associated with her EEG findings. The imaging and EEG findings were congruent, confirming this tuber as the source of her seizures.

Until the patient was 3 months of age, recorded epileptic episodes were subclinical. She then developed seizures associated with a startle. By 5 months of age, semiology had progressed to eye gaze deviation and arm raising, which correlated with right frontocentral epileptic events on EEG. She was having approximately 8 clinical seizures per day, and subclinical seizures were detected in clusters occurring every 5-20 minutes. She was given 6 different AEDs, with little to no improvement. Surgical options were therefore discussed at our Pediatric Epilepsy Board, and she was thought to be a candidate for either open resection or laser ablation of her dominant right frontocentral tuber. Risks and benefits were discussed in detail regarding the two surgical techniques, and her family desired to proceed with laser ablation rather than resection. The family understood the novel application of this device due to their child's age, as well as its potential challenges and the plan to convert to image-guided craniotomy if there were technical difficulties with the ablation system. The infant successfully underwent an MRgLITT procedure using the Monteris Medical NeuroBlate System (Monteris Medical, Inc.).

\section{Surgical Technique and Planning}

The patient was admitted the day prior to surgery to receive 24 hours of intravenous dexamethasone $(0.2 \mathrm{mg}$ / $\mathrm{kg} / 24 \mathrm{hrs}$ divided into thirds, with a dose given every 8 hours) to decrease expected intracranial swelling from the procedure.

The patient was brought to the IMRIS 3-T intraoperative MRI suite and general anesthesia was induced. The patient was placed on a gel horseshoe headholder and secured to the table and headframe by using silk tape and foam. Careful attention was taken in positioning to avoid distorting the scalp or skull in this infant with open fontanelles. A Brainlab optical image guidance reference frame was secured to the horseshoe. Surface mapping was used to register the patient's preoperative MRI.

The NeuroBlate system is usually passed intracranially through a titanium cranial bolt. Due to our patient's thin skull at 6 months of age, however, this bolt would have been too thick and heavy to use. Therefore, the Monteris AXiiiS stereotactic miniframe was used as a skull-mounted trajectory guide. This system was chosen for the miniframe, which uses multiple points of fixation that provide improved safety and stability in the infant skull, as well as small screws for which the depth could be controlled to decrease the risk of CSF leakage or intracranial injury. This frame provides 3 points of fixation to distribute the weight of the probe. Each of the 3 telescoping legs attaches with a skull screw and 3 scalp spikes. Each leg was placed on a different portion of the skull: one of the legs was placed on the right parietal region, one was placed on the contralateral left side of the sagittal suture, and the last one was placed on the right side anterior to the coronal suture, just behind the hairline. The fixation points were placed on 3 different skull bones for the shared weight of the device and to improve pullout strength and dynamics once the ablation probe was inserted. Care was taken to prevent placing any of the feet directly over a venous sinus, because the screws do travel full thickness through the skull. The skull was measured to be 3-4 mm in maximal thickness for this patient based on age and her imaging. The miniframe screws will reach a depth of up to 4.5 $\mathrm{mm}$. For this case, they were left $1 \mathrm{~mm}$ proud above the frame. As noted above, careful consideration of the skull thickness must be taken into consideration when planning placement. Each incision must be closed at the end of the case and monitored in the postoperative period for potential CSF leakage in the event of dural laceration.

Once the frameless stereotactic registration and appropriate placement of the AXiiiS miniframe were verified, the appropriate entry point and trajectory for the laser ablation probe were confirmed. Intraoperative reference marks were placed on the scalp to provide intraoperative stereotactic verification. Careful attention was taken not to disturb or deform her scalp or skull because that would have impaired our accuracy. Malpositioning of the laser probe has been reported in up to $6.5 \%$ of cases. ${ }^{35}$ Thus, without rigid fixation in an infant, we recommend the use of fiducials or additional intraoperative reference points to confirm accurate registration after placement of the laser tripod system (Fig. 2). After the miniframe is placed, if there is a concern for registration accuracy, an additional MRI sequence should be obtained prior to passing the laser probe.

After securing the AXiiis miniframe to the skull and confirming accurate registration and trajectory for the probe, a small scalp incision was made for the laser entry point. The skull was drilled with high-speed burr. The dura was coagulated and opened sharply. The laser probe was then passed to the premeasured target within the right frontal tuber.

The patient was taken off the horseshoe and slid down 


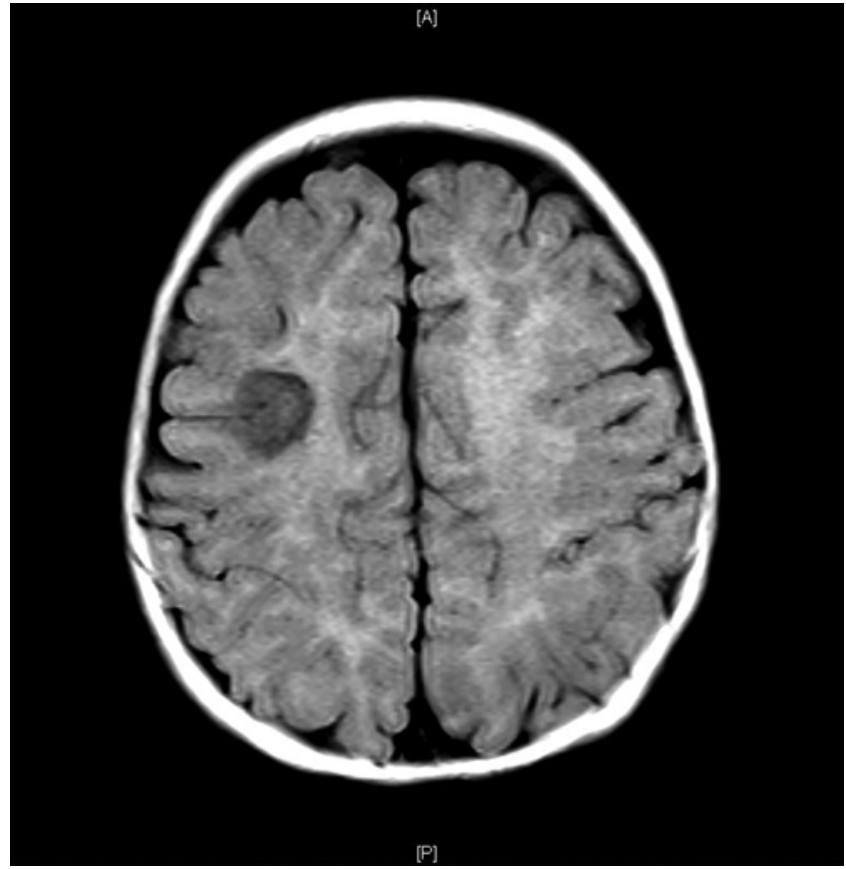

FIG. 1. Pretreatment axial FLAIR MR image demonstrating a right frontal cortical tuber

onto the MRI-compatible table, with careful attention being paid to not disrupting the laser tripod. The IMRIS intraoperative MRI scanner was slid around the patient and MR images were obtained to confirm appropriate location of the probe within the lesion. The ablation was then begun. The ablation proceeded with the goal of reaching $43^{\circ} \mathrm{C}$ for at least 10 minutes for the entire tuber.

The NeuroBlate system uses a $\mathrm{CO}_{2}$ gas-cooled Nd:YAG laser and thermocouple that delivers controlled laser energy to the intended target. ${ }^{19}$ Side-firing and diffuse-tip probes are available. The diffuse-tip probe is available in a smaller $(2.2-\mathrm{mm})$ diameter and therefore was used in this case. The NeuroBlate system connects with the MRI system and provides real-time thermographic data including thermal-damage-threshold lines (Fig. 3). These lines correspond with the limit of permanent damage and coagulation necrosis. ${ }^{30}$

Once ablation was completed, an MRI session was performed to confirm that the entire lesion had been successfully treated. Postoperative edema outside the lines of permanent damage was noted in Fig. 4. The patient was treated with intravenous steroids for 3 days postoperatively, followed by an oral steroid taper for 1 week, and she remained clinically asymptomatic.

Three months postoperatively she began to sit up and to crawl, and her development significantly improved. She was free of clinical seizures for 5 months postoperatively, but then she began to develop a new seizure type with head shaking and jerking movements. Three clinical seizures localizing to the right parietal area were noted during 2 days of noninvasive EEG monitoring performed 6 months postoperatively. Her development has continued to improve and she remains on AEDs. Her MRI shows the expected cavitation at the right frontal region in the area

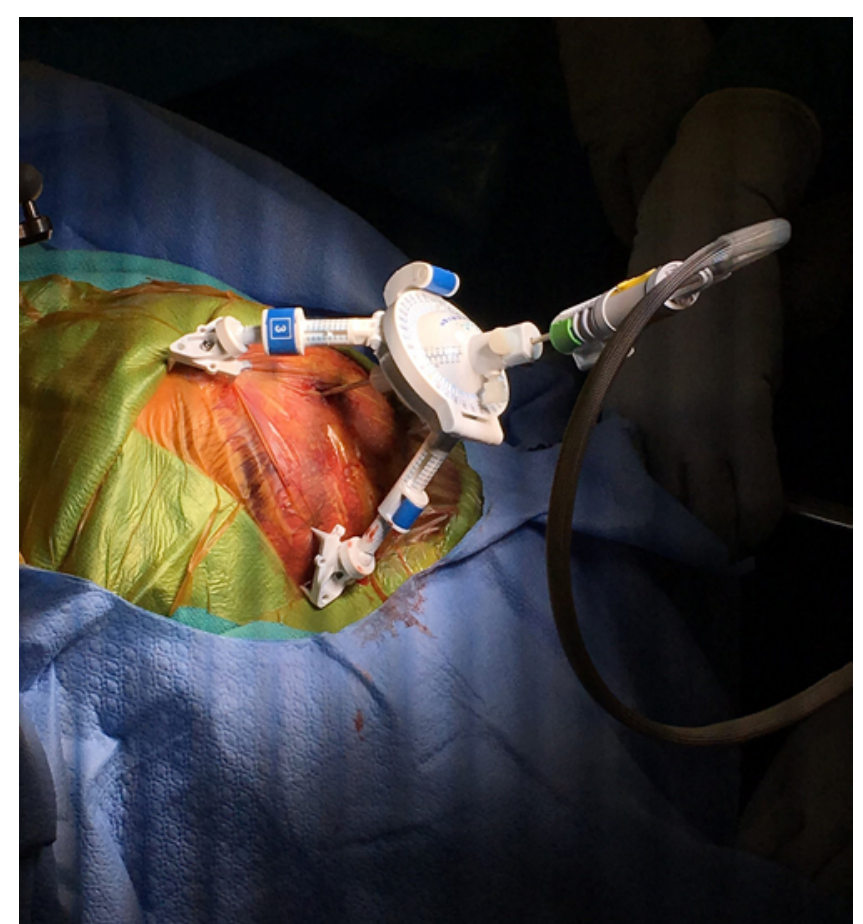

FIG. 2. Intraoperative setup. Initial surface matching registration was performed and additional intraoperative reference landmarks were placed on the scalp to confirm accuracy of registration during the application of the NeuroBlate AXiiiS miniframe tripod to the infant's head. Once the laser probe was inserted, the Brainlab frame was removed and the infant was transferred into the intraoperative MRI scanner to confirm accuracy of placement prior to ablation. Careful attention must be paid to avoid disrupting the probe when transferring the patient. Figure is available in color online only.

of the ablated tuber, as well as additional cortical tubers including a right parietal tuber. Figure 4 left demonstrates the immediate postablation MRI; Fig. 4 right shows her 6-month follow-up MRI.

\section{Discussion}

TSC is a multisystem genetic disorder that affects the CNS, with the development of cortical and subcortical lesions. Two gene mutations, tuberous sclerosis complex 1 (TSC1) and tuberous sclerosis complex 2 (TSC2) have been identified and can display an autosomal dominant inheritance. ${ }^{21}$ The majority of cases diagnosed, however, are believed to result from sporadic mutations. ${ }^{16,23,33}$

As in our patient, seizure onset typically begins in the 1st year of life. Seizures are commonly associated with the cortical tubers, and as a result, many patients present with focal or multifocal and bilateral semiology depending on the number and location of tubers. ${ }^{8} 10$ Up to $85 \%$ of patients with TSC will develop drug-resistant epilepsy (DRE). In infants, focal seizures may also progress to infantile spasms. ${ }^{9}$ Children with younger age at onset, more severe seizures, longer treatment duration, and DRE are at an increased risk for developing neurocognitive disabilities and significant comorbidities. ${ }^{2,3,6,39}$ Functional outcome and quality of life are improved if epilepsy can 


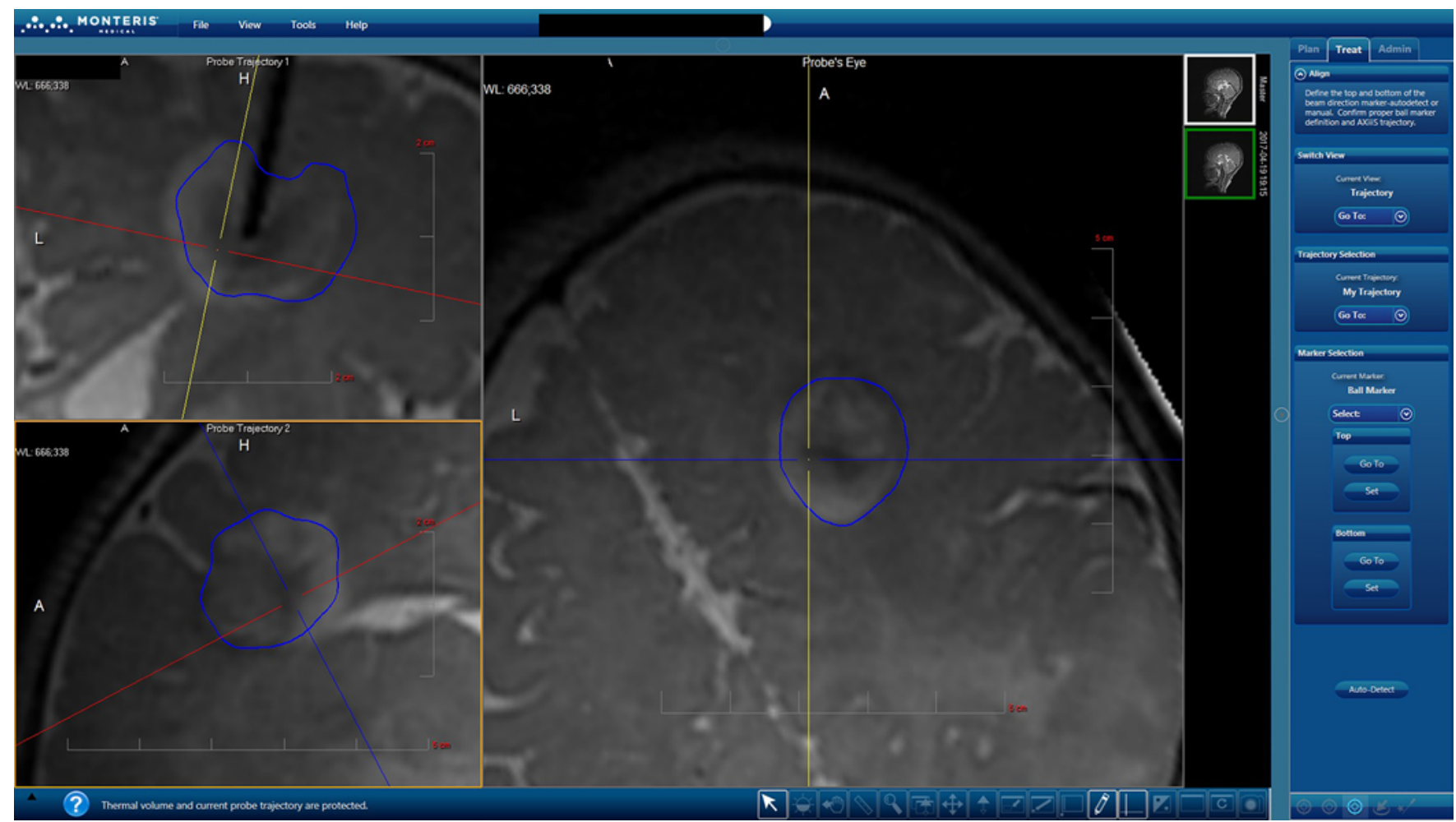

FIG. 3. Intraoperative view demonstrating laser located within the lesion. The area of expected ablation at the tuber is outlined in blue. Figure is available in color online only.

be controlled at an early age. $5,39,45,46$ Therefore, patients with DRE are being evaluated for surgical interventions at younger ages, making minimally invasive techniques attractive.

In patients with multiple tubers, seizure localization can be challenging. Often, these patients undergo multiple craniotomies or multistage invasive monitoring and resection. ${ }^{38,45,46}$ A traditional craniotomy for seizure focus resection carries up to $3 \%-6 \%$ reported major surgical morbidity and $1.4 \%$ 30-day mortality. ${ }^{1,27,41}$ Less invasive monitoring techniques such as stereoelectroencephalography may reduce this morbidity and can be combined with LITT. ${ }^{26}$ Once seizures can be reliably localized, patients should be considered for surgical intervention. Tubers may have an epileptogenic zone of cortex surrounding the lesion..$^{25,29,31,32}$ Epileptiform discharges have been recorded from the abnormal perituberal cortex as well as from the tuber. The entire epileptogenic zone must be ablated for treatment success. In TSC, if an epileptogenic focus can be associated with a specific tuber, $57 \%$ of children will achieve seizure freedom and up to $75 \%$ will obtain an overall improvement or reduction in seizure frequency at 1 year. ${ }^{15,22,42}$ Predictors of good outcomes in patients with TSC include the absence of generalized seizures, no or mild developmental delay, and concordance between lesions demonstrated on EEG and MRI. ${ }^{15}$ Development of seizures from additional cortical tubers or multilobar disease remains a risk that must be discussed with the family prior to surgery. Patients with TSC require lifelong clinical follow-up. Annual or biennial imaging, especially in infants and toddlers, can detect new cortical tubers as well as evaluate for formation of subependymal giant cell astrocytoma, and aid in diagnosis if new symptoms develop.

One of the main risks of neurosurgery in infants is blood loss, because the blood volume for a 6-month-old infant is approximately $90 \mathrm{ml} / \mathrm{kg} .{ }^{12}$ With limited blood volume, infants are less tolerant of the hemodynamic shifts that occur during a craniotomy. Furthermore, at this age, myelination is not complete and the brain lacks turgor, making it not as amenable to standard microsurgical techniques.
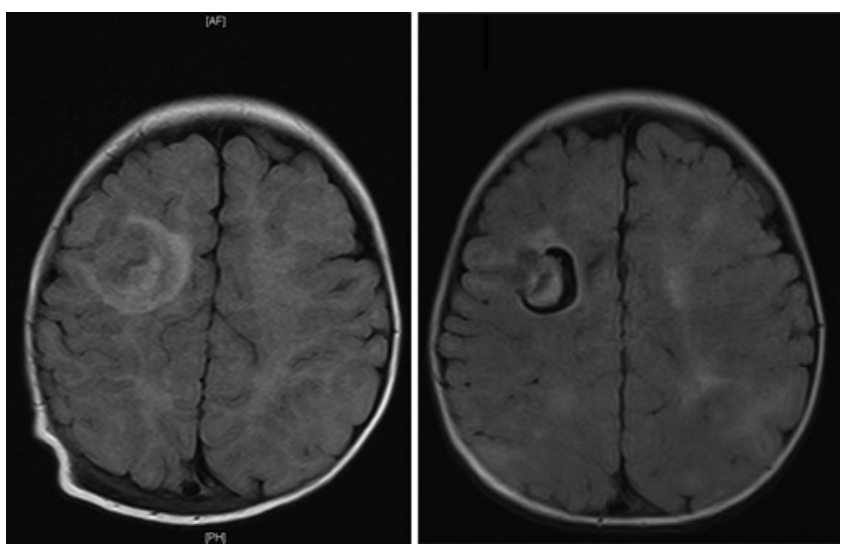

FIG. 4. Left: Immediate posttreatment axial FLAIR MR image demonstrating surrounding edema. Right: Six-month posttreatment axial FLAIR MR image demonstrating lesion ablation. 
Therefore, less invasive treatments are ideal for this population. As noted above, the advantages of MRgLITT over craniotomy include decreased morbidity, a smaller incision, shorter hospital stay, reduced blood loss, and reduced postoperative pain. MRgLITT can ablate the epileptogenic zone with less damage to normal surrounding brain, with real-time thermal monitoring. ${ }^{34}$ Limitations of MRgLITT include the inability to treat large lesions and irregular lesions adjacent to major blood vessels. The need for cranial fixation in a stereotactic frame or cranial pins is a relative contraindication. As noted above, previously described techniques involve stereotactic frames or fixation in cranial pins. ${ }^{11,26,34,43,44}$ Here, we have presented the steps for a frameless navigation technique with the modified use of the NeuroBlate AXiiiS miniframe system with stereotactic intraoperative reference points to provide accurate laser ablation therapy for an infant.

\section{Conclusions}

MRI-guided laser-induced thermal ablation for epilepsy is an exciting new minimally invasive technique whose applications are continuously expanding. With this report, we demonstrate a technique that can be applied to infants with DRE. Although this technique may not offer the same degree of accuracy as a frame-based system, intraoperative steps can be taken to confirm accuracy, and intraoperative imaging will identify the location of the probe before ablative techniques are applied. Our results are limited, with only one patient and short-term follow-up, and further research is needed to confirm the long-term clinical effectiveness. However, this technique can expand the potential population of patients who may benefit from this therapy.

\section{Key Points}

- MRI-guided laser ablation can be performed in infants with an open fontanelle by using a miniframe tripod and intraoperative reference points to improve stereotactic accuracy.

- This technique can permit surgical treatment of TSCassociated epilepsy in a more minimally invasive fashion than is used currently.

- The successful treatment of this patient expands the indications for this less invasive method.

\section{References}

1. Behrens E, Schramm J, Zentner J, König R: Surgical and neurological complications in a series of 708 epilepsy surgery procedures. Neurosurgery 41:1-10, 1997

2. Berg AT, Zelko FA, Levy SR, Testa FM: Age at onset of epilepsy, pharmacoresistance, and cognitive outcomes: a prospective cohort study. Neurology 79:1384-1391, 2012

3. Brooks-Kayal AR, Bath KG, Berg AT, Galanopoulou AS, Holmes GL, Jensen FE, et al: Issues related to symptomatic and disease-modifying treatments affecting cognitive and neuropsychiatric comorbidities of epilepsy. Epilepsia 54 (Suppl 4):44-60, 2013

4. Catenoix H, Mauguière F, Montavont A, Ryvlin P, Guénot M, Isnard J: Seizures outcome after stereoelectroencephalography-guided thermocoagulations in malformations of cortical development poorly accessible to surgical resection. Neurosurgery 77:9-15, 2015
5. Chipaux M, Dorfmüller G, Fohlen M, Dorison N, Metten MA, Delalande O, et al: Refractory spasms of focal onset-A potentially curable disease that should lead to rapid surgical evaluation. Seizure 51:163-170, 2017

6. Chu-Shore CJ, Major P, Camposano S, Muzykewicz D, Thiele EA: The natural history of epilepsy in tuberous sclerosis complex. Epilepsia 51:1236-1241, 2010

7. Curatolo P: Neurological manifestations of tuberous sclerosis complex. Childs Nerv Syst 12:515-521, 1996

8. Curatolo P, Bombardieri R, Jozwiak S: Tuberous sclerosis. Lancet 372:657-668, 2008

9. Curatolo P, Bombardieri R, Verdecchia M, Seri S: Intractable seizures in tuberous sclerosis complex: from molecular pathogenesis to the rationale for treatment. J Child Neurol 20:318-325, 2005

10. Curatolo P, D’Argenzio L, Cerminara C, Bombardieri R: Management of epilepsy in tuberous sclerosis complex. Expert Rev Neurother 8:457-467, 2008

11. Curry DJ, Gowda A, McNichols RJ, Wilfong AA: MRguided stereotactic laser ablation of epileptogenic foci in children. Epilepsy Behav 24:408-414, 2012

12. Darrow DC, Soule HC, Buckman TE: Blood volume in normal infants and children. J Clin Invest 5:243-258, 1928

13. Du VX, Gandhi SV, Rekate HL, Mehta AD: Laser interstitial thermal therapy: A first line treatment for seizures due to hypothalamic hamartoma? Epilepsia 58 (Suppl 2):77-84, 2017

14. Esquenazi Y, Kalamangalam GP, Slater JD, Knowlton RC, Friedman E, Morris SA, et al: Stereotactic laser ablation of epileptogenic periventricular nodular heterotopia. Epilepsy Res 108:547-554, 2014

15. Fallah A, Guyatt GH, Snead OC III, Ebrahim S, Ibrahim GM, Mansouri A, et al: Predictors of seizure outcomes in children with tuberous sclerosis complex and intractable epilepsy undergoing resective epilepsy surgery: an individual participant data meta-analysis. PLoS One 8:e53565, 2013

16. Fryer AE, Chalmers A, Connor JM, Fraser I, Povey S, Yates $\mathrm{AD}$, et al: Evidence that the gene for tuberous sclerosis is on chromosome 9. Lancet 1:659-661, 1987

17. Gonzalez-Martinez J, Vadera S, Mullin J, Enatsu R, Alexopoulos AV, Patwardhan R, et al: Robot-assisted stereotactic laser ablation in medically intractable epilepsy: operative technique. Neurosurgery 10 (Suppl 2):167-172, discussion 172-173, 2014

18. Gross RE, Willie JT, Drane DL: The role of stereotactic laser amygdalohippocampotomy in mesial temporal lobe epilepsy. Neurosurg Clin N Am 27:37-50, 2016

19. Hawasli AH, Bagade S, Shimony JS, Miller-Thomas M, Leuthardt EC: Magnetic resonance imaging-guided focused laser interstitial thermal therapy for intracranial lesions: singleinstitution series. Neurosurgery 73:1007-1017, 2013

20. Heisterkamp J, van Hillegersberg R, Zondervan PE, IJzermans JN: Metabolic activity and DNA integrity in human hepatic metastases after interstitial laser coagulation (ILC). Lasers Surg Med 28:80-86, 2001

21. Jansen FE, Braams O, Vincken KL, Algra A, Anbeek P, Jennekens-Schinkel A, et al: Overlapping neurologic and cognitive phenotypes in patients with TSC1 or TSC2 mutations. Neurology 70:908-915, 2008

22. Jansen FE, van Huffelen AC, Algra A, van Nieuwenhuizen $\mathrm{O}$ : Epilepsy surgery in tuberous sclerosis: a systematic review. Epilepsia 48:1477-1484, 2007

23. Kandt RS, Haines JL, Smith M, Northrup H, Gardner RJ, Short MP, et al: Linkage of an important gene locus for tuberous sclerosis to a chromosome 16 marker for polycystic kidney disease. Nat Genet 2:37-41, 1992

24. Kang JY, Wu C, Tracy J, Lorenzo M, Evans J, Nei M, et al: Laser interstitial thermal therapy for medically intractable mesial temporal lobe epilepsy. Epilepsia 57:325-334, 2016 
25. Kannan L, Vogrin S, Bailey C, Maixner W, Harvey AS: Centre of epileptogenic tubers generate and propagate seizures in tuberous sclerosis. Brain 139:2653-2667, 2016

26. Karsy M, Guan J, Ducis K, Bollo RJ: Emerging surgical therapies in the treatment of pediatric epilepsy. Transl Pediatr 5:67-78, 2016

27. Kerezoudis P, McCutcheon B, Murphy ME, Rajjoub KR, Ub D, Habermann EB, et al: Thirty-day postoperative morbidity and mortality after temporal lobectomy for medically refractory epilepsy. J Neurosurg 128:1158-1164, 2018

28. Lewis EC, Weil AG, Duchowny M, Bhatia S, Ragheb J, Miller I: MR-guided laser interstitial thermal therapy for pediatric drug-resistant lesional epilepsy. Epilepsia 56:1590-1598, 2015

29. Ma TS, Elliott RE, Ruppe V, Devinsky O, Kuzniecky R, Weiner HL, et al: Electrocorticographic evidence of perituberal cortex epileptogenicity in tuberous sclerosis complex. $\mathbf{J}$ Neurosurg Pediatr 10:376-382, 2012

30. Missios S, Bekelis K, Barnett GH: Renaissance of laser interstitial thermal ablation. Neurosurg Focus 38(3):E13, 2015

31. Mohamed AR, Bailey CA, Freeman JL, Maixner W, Jackson GD, Harvey AS: Intrinsic epileptogenicity of cortical tubers revealed by intracranial EEG monitoring. Neurology 79:2249-2257, 2012

32. Moshel YA, Elliott R, Teutonico F, Sellin J, Carlson C, Devinsky O, et al: Do tubers contain function? Resection of epileptogenic foci in perirolandic cortex in children with tuberous sclerosis complex. Epilepsia 51:1242-1251, 2010

33. Osborne JP, Fryer A, Webb D: Epidemiology of tuberous sclerosis. Ann N Y Acad Sci 615:125-127, 1991

34. Prince E, Hakimian S, Ko AL, Ojemann JG, Kim MS, Miller JW: Laser interstitial thermal therapy for epilepsy. Curr Neurol Neurosci Rep 17:63, 2017

35. Pruitt R, Gamble A, Black K, Schulder M, Mehta AD: Complication avoidance in laser interstitial thermal therapy: lessons learned. J Neurosurg 126:1238-1245, 2017

36. Reimer P, Bremer C, Horch C, Morgenroth C, Allkemper T, Schuierer G: MR-monitored LITT as a palliative concept in patients with high grade gliomas: preliminary clinical experience. J Magn Reson Imaging 8:240-244, 1998

37. Rolston JD, Chang EF: Stereotactic laser ablation for hypothalamic hamartoma. Neurosurg Clin N Am 27:59-67, 2016

38. Romanelli P, Najjar S, Weiner HL, Devinsky O: Epilepsy surgery in tuberous sclerosis: multistage procedures with bilateral or multilobar foci. J Child Neurol 17:689-692, 2002

39. Roth J, Olasunkanmi A, MacAllister WS, Weil E, Uy CC, Devinsky O, et al: Quality of life following epilepsy surgery for children with tuberous sclerosis complex. Epilepsy Behav 20:561-565, 2011
40. Schwabe B, Kahn T, Harth T, Ulrich F, Schwarzmaier HJ: Laser-induced thermal lesions in the human brain: short- and long-term appearance on MRI. J Comput Assist Tomogr 21:818-825, 1997

41. Spencer S, Huh L: Outcomes of epilepsy surgery in adults and children. Lancet Neurol 7:525-537, 2008

42. Téllez-Zenteno JF, Hernández Ronquillo L, Moien-Afshari F, Wiebe S: Surgical outcomes in lesional and non-lesional epilepsy: a systematic review and meta-analysis. Epilepsy Res 89:310-318, 2010

43. Tovar-Spinoza Z, Choi H: Magnetic resonance-guided laser interstitial thermal therapy: report of a series of pediatric brain tumors. J Neurosurg Pediatr 17:723-733, 2016

44. Tovar-Spinoza Z, Choi H: MRI-guided laser interstitial thermal therapy for the treatment of low-grade gliomas in children: a case-series review, description of the current technologies and perspectives. Childs Nerv Syst 32:1947-1956, 2016

45. Weiner HL: Tuberous sclerosis and multiple tubers: localizing the epileptogenic zone. Epilepsia 45 (Suppl 4):41-42, 2004

46. Weiner HL, Ferraris N, LaJoie J, Miles D, Devinsky O: Epilepsy surgery for children with tuberous sclerosis complex. J Child Neurol 19:687-689, 2004

47. Willie JT, Laxpati NG, Drane DL, Gowda A, Appin C, Hao $\mathrm{C}$, et al: Real-time magnetic resonance-guided stereotactic laser amygdalohippocampotomy for mesial temporal lobe epilepsy. Neurosurgery 74:569-585, 2014

\section{Disclosures}

The authors report no conflict of interest concerning the materials or methods used in this study or the findings specified in this paper.

\section{Author Contributions}

Conception and design: all authors. Acquisition of data: all authors. Analysis and interpretation of data: all authors. Drafting the article: Hooten. Critically revising the article: all authors. Reviewed submitted version of manuscript: all authors. Study supervision: Muh.

\section{Correspondence}

Kristopher G. Hooten: Duke University, Durham, NC. kristopher. hooten@neurosurgery.ufl.edu. 